same infection followed a different course in well-off and poor children. The medical treatment given to all groups was similar; the contrast in morbidity and mortality might have been even greater had no treatment been given.

These findings suggest that the effect of undernutrition in these children may have been to increase the severity of common childhood infections rather than to produce detectable signs of nutritional deficiency. This study underlines the importance of programmes of nutritional education and the provision of suitable low-cost highcalorie high-protein foods to upgrade the nutritional status of the preschool population in developing countries. Foods of this type are particularly important in urban areas where calories are especially likely to be inadequate owing to poverty and a cash-based economy. Such programmes, however, will be undermined if suitable facilities for the prevention and treatment of common childhood infestations and infections are not simultaneously provided.

I acknowledge the generous support and advice given by Professors W. R. F. Collis, R. G. Hendrickse and W. W. Holland, and Drs O. Adeniji-Jones, D. Morley and J. McFie. This study forms part of a thesis submitted for the MD degree of the University of Cambridge. The work on which it is based was supported by a subvention from the Federal Ministry of Health to the Institute of Child Health, University of Ibadan.

\title{
REFERENCES
}

Bruce-Chwatt, L. J. (1952). Ann. trop. Med. Parasit. 46, I73.

Draper, C. C. (I960). Br. med. \%. ii, 1480 .

McFie, J. (1967). Br. F. Nutr. 21, 257.

Miller, D. S. \& Payne, P. R. (1964). Proc. Nutr. Soc, 23, I I.

Rea, J. N. (1969). Interactions of nutrition and infection. MD Thesis, University of Cambridge.

Rea, J. N. (1970). Hum. Biol. (In the Press.)

Tanner, J. M., Whitehouse, R. H. \& Takaishi, M. (1966). Archs Dis. Childh. 41, 454.

Valadian, I., Stuart, H. C. \& Reed, R. B. (I96I). Monogr. Soc. Res. Child Der., no. 81.

Whitehead, R. G. \& Dean, R. F. A. (I964). Am. F. clin. Nutr. r4, 320.

WHO (1965). Tech. Rep. Ser. Wld Hlth Org. no. 314.

Wittman, W., Moodie, A. D., Hansen, J. D. L. \& Brock, J. F. (1967). Ciba Fdn Study Grps no. 3I, p. 73 .

\section{Nutrition education in rural societies}

By David Morley, Institute of Child Health, $3^{\circ}$ Guilford Street, London WCI

Prominent in the Department of Human Nutrition in the London School of Hygiene and Tropical Medicine in the days of the late Professor Platt was a diagram showing the interrelationships of the many disciplines concerned with nutrition (Fig. r). Professor Platt believed that among these disciplines the medically qualified nutritionist had a special responsibility. Because it was only the doctor who saw the effects of malnutrition, particularly on children, the bringing together of the 


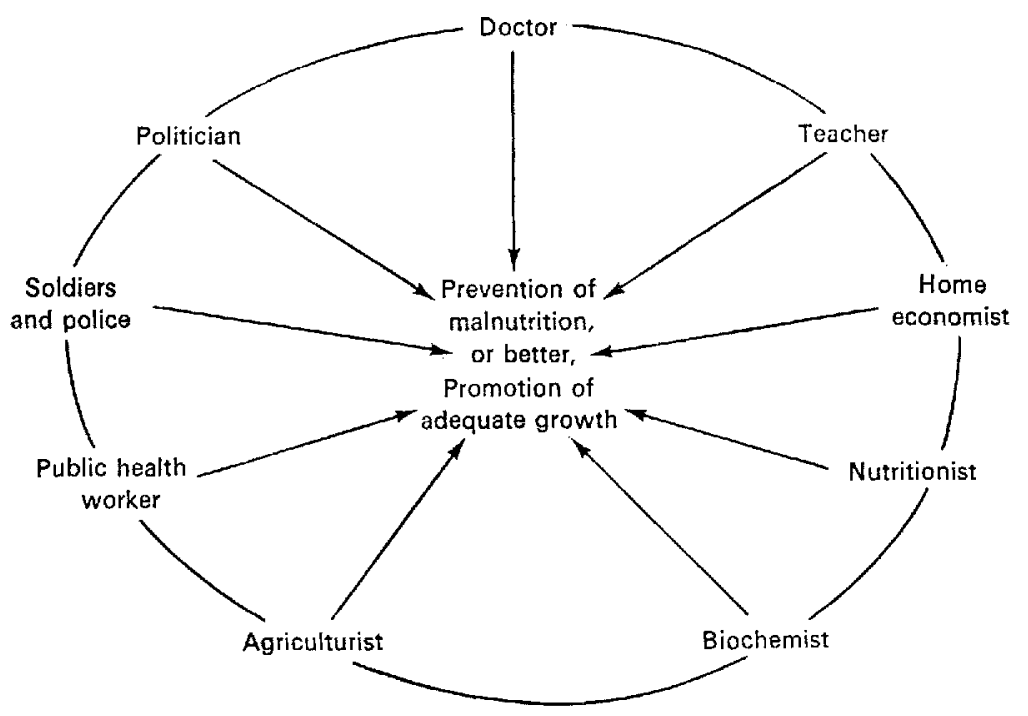

Fig. I. Interrelationships of disciplines in preventing malnutrition.

other disciplines should fall on his shoulders, as it is only the doctor who can identify the type, the severity and the frequency of malnutrition in the population.

Professor Platt put his beliefs into practice in the organization of the LondonIbadan nutrition course. The course was attended by workers in many disciplines, for example there were doctors, nurses, agriculturists, veterinarians, home economists, nutritionists, biochemists, and those concerned with health education. I was privileged to be involved in the organization and teaching of these groups. Their heterogeneous background was a great challenge to both students and teachers. During the 8 months of study together, both in London and in Nigeria, the group developed an attitude to nutrition which the various members took back to their countries, where many of them gained positions of importance and influence. This combination of teaching in a European-based university with a university in a developing country offers many advantages which are likely to be more appreciated as the cost of long-distance travel makes this type of course more possible in the next decade.

\section{Problems of communication}

A poor level of communication between the professorial staff and their students the world-over has led to revolts of students in many countries. As an outcome of this, more time and money is at last being spent on research into educational method and evaluation of its effect. The rural society cannot revolt when those sent to educate them do not communicate effectively, but instead they carry on with the same knowledge and attitudes as their parents. Attempts are being made to communicate more effectively with rural populations, and a few of these will be briefly described here. 
Many concepts that are generally assumed to be held by all adults may not be understood by illiterates. Holmes (I964) showed that perspective was not understood. Recently, Fuglesang (1969) has shown that conservation of mass or number and the straight line as the shortest distance between two points are concepts not held by many illiterates, although periods of only 2 years of schooling allow them to be understood. Fuglesang's studies have also shown that the photograph with the background cut away is more likely to be understood than line or shadow drawings, and posters in this form have led to a far greater understanding of malnutrition by the rural population of Zambia, where levels of literacy are low.

\section{Nutrition rehabilitation centres}

The setting up of a nutrition rehabilitation centre recognizes that changing people's attitudes to food requires time, patience and skill. Nutrition rehabilitation centres were pioneered in South America (Bengoa, 1967), and then spread to Africa and Asia. Some centres in urban cities are open during the day-time only. Most, however, are residential, the mothers remaining in them for 3-4 weeks, or sometimes months, during which time they are taught to modify and improve the diets that they give to their children. Perhaps nutrition rehabilitation centres need to be near enough to health centres or hospitals to obtain medical supervision, but their day-today direction is better undertaken by an enthusiast with a background probably in some other discipline, such as education or home economics. The mother must see her child improving as a result of better feeding in surroundings not dissimilar to those of her own, and without the trappings of Western medicine. Nutrition teaching will fall on deaf ears in children's wards where the mother believes the syringe and white coat cure her child.

A novel approach to nutrition rehabilitation has been made by King, Beghin, Fougere, Dominique, Grinker \& Foucauld (1968) in Haiti. He introduced a nutrition worker into a village where she lived in a hut, and invited several of the ill-nourished children, with their mothers, to live with her. The village, as well as the mothers, saw these children improving, and after a few months, when their health was fully recovered by using local foods which had been largely produced locally, the children, were discharged, and a further group of poorly nourished children invited to live with the worker.

Another form of nutrition rehabilitation centre has been set up by Stanfield in East Africa, where he has developed an effective combination of a comprehensive young children's clinic (Under-Fives' Clinic), a nutrition rehabilitation centre, and a demonstration farm at village level. Some of the buildings for this unit have been put up using local but improved building methods, and local initiative and effort. The father can see how his plot of land may produce an increased cash crop, and yet at the same time feed his family better. Two cows of improved stock, which are stall-fed, produce milk for the undernourished children, while the clinic workers can keep the mother and the children under supervision, and the Under-Fives' Clinic is a meeting place where the mothers can bring their children who have 
symptoms, for which they may receive very low-cost medicines, but at the same time preventive inoculations, and nutrition education is going on all the time. The nutrition education is based on the child's own growth curve on a simple weight chart which is described below.

\section{The use of 'The Road to Health' card}

Medical services for children in rural societies in most developing countries are inefficient and inadequate. For many reasons, medical records are non-existent, or have been well likened to 'bus tickets'. These 'bus tickets' carry the child through one illness, and usually contain little more than the diagnosis and medicine supplied. Such a system cannot be the basis of adequate child care. A record system developed more than ro years ago in West Africa has been found to be effective, and has been widely adopted in East Africa and elsewhere. The records consist of a weight chart, a clinic card, and a strong polyethylene envelope. The details of these cards have been recorded elsewhere (Morley, I968a), and recently their positive approach to encourage health through growth has led to their being called 'The Road to Health' cards in Malawi.

The most striking difference between this chart and charts previously used is the system by which the passage of time is recorded. Experience in many countries has shown that the most severe limitation to the use of weight charts is the need to calculate the age of the child on each attendance before the curve can be plotted. Instead of the record of the age being in months along the base of the chart, with this type of chart a calendar is constructed which starts with the birth of the child (Fig. 2). Once this has been done-and it takes no more than two or three minutesthere is no need to calculate the age of the child. Instead, the weight is plotted in the month in which the weighing is done, and this weight is joined up with the weights in previous months to construct a curve, which is the best indication of the progress of the child's nutrition. The aim of the health worker will always be to see that the child gains weight steadily. A flattening of the weight curve is a danger sign that usually precedes malnutrition by many months (Morley, I968b). A return to normal weight gain is the first and most effective guide to success in improving the child's diet through teaching. The health worker now has the more positive objective of 'promoting adequate growth' and not just 'preventing malnutrition.'

The chart contains a space in which can be written the signs that indicate the child is at risk. These 'reasons for special care' need to be known for each community, and allow the child welfare services to be directed at the portion of the community which most needs them. This is unlike present 'Well Baby' clinics, which are largely concerned with the section of the community that least needs help.

The chart is printed on tough card, designed to be kept in the child's home till the age of 5 years. In those communities where these cards have been introduced, the mothers keep them well, and few, if any, are lost, fewer in fact, than are mislaid or misfiled in the local health centre. By keeping the chart in the home, the mother can be taught to use it wherever and whenever she seeks medical help for her child. 
The chart is available in the home for visits, not only those made by medical workers but also by agricultural extension workers and workers from other disciplines, who can soon learn to understand the valuable information given by the child's weight curve.

\section{Reasons for special care}

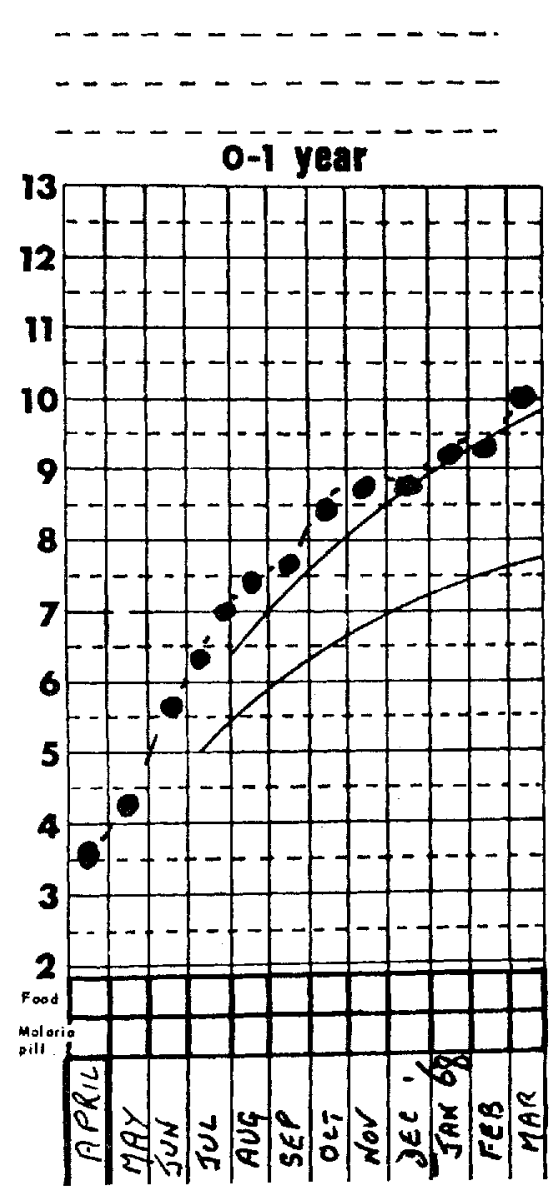

1-2 years

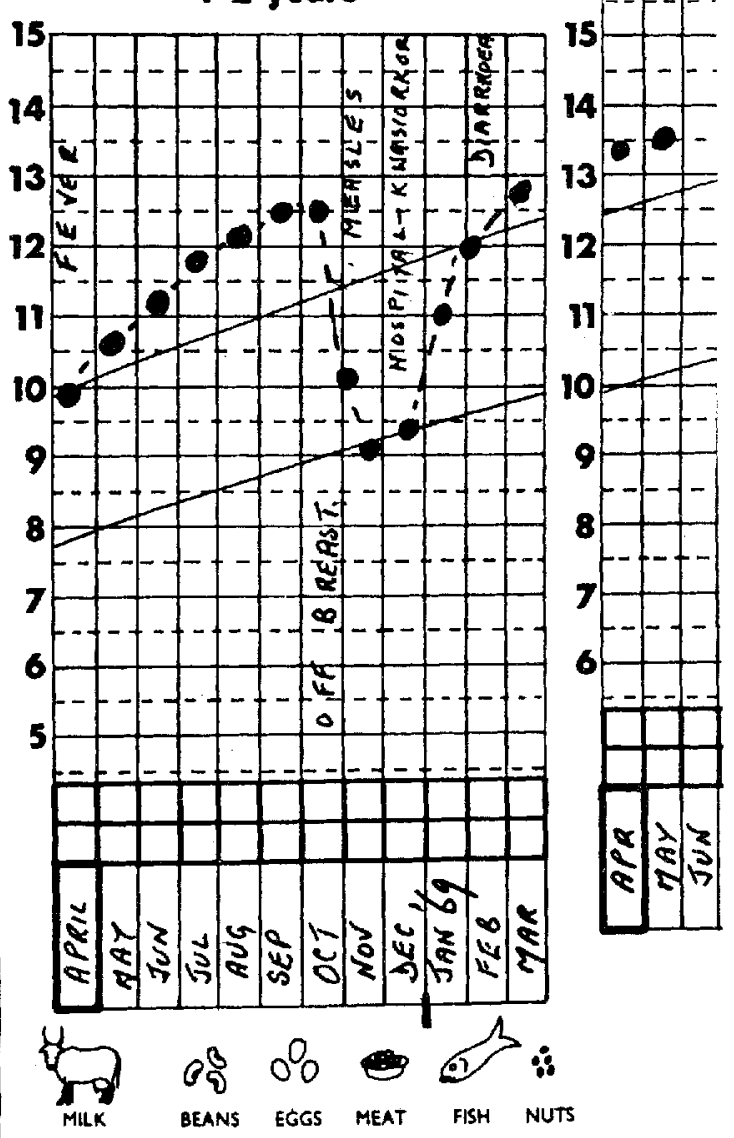

Fig. 2. The 'Road to Health' card. This type of chart is now widely used in East and West Africa and is gaining acceptance in Asia. In this example note the dramatic loss in weight following an attack of measles in November r 968 .

Introduction of weight charts allows information on the individual child to move in two directions. The health worker and any other visitor to the home can instruct the mother how her child is doing and, on the other hand, information can be obtained for local and central authorities on the take-up of health services and on the health of the children of the area. This information is collected by visiting a randomized sample of the homes in the community, and it offers a method for analysing any improvement in the nutritional status of the children in the area. 


\section{Interaction of nutrition and infection}

The interaction between nutrition and infection was a subject that Professor Platt studied and wrote upon over many years. His contribution to this subject, and those of many others, have been collected recently in a monograph prepared for the World Health Organization by Scrimshaw, Taylor \& Gordon (1968). This monograph draws attention to the two separate concepts that have to be considered. Both are well exemplified by measles, and each has considerable relevance in nutrition education.

The first concept is that infection makes the nutrition of the child worse. A study of many thousands of weight charts revealed that measles led to more weight loss than any of the other common infections in West Africa. The dramatic loss of weight following measles is shown in Fig. 2. It will be seen that $26 \%$ of the weight of the child was lost following measles, which occurred at the same time as the mother took the child off the breast. The records of 220 children in a longitudinal study were also examined, and it was found that a quarter of the children lost $10 \%$ of their weight, and $15 \%$ of the children took more than 3 months to recover their previous weight following measles (Morley, Woodland \& Martin, I963). Preventing this loss of weight, and maintaining a child's nutrition, need to be major considerations in managing this disease; these must have a high priority in nutrition education, and may have to be done in the face of local taboos and beliefs in rural areas, which may severely limit the child's intake of calories and protein foods during the disease. Local cultures recognize this relation between nutrition and disease, and frequently the patient asks the doctor what special foods should and should not be eaten. Unfortunately, most doctors are not adequately trained in this aspect of nutrition, nor do they recognize its importance. However, with the use of weight charts and clearly visible evidence of the effect of the disease on the child's nutrition, greater attention can be given to this teaching, and the changes in the child's weight curve are an effective measure of its success.

The second concept is that the malnourished child is likely to suffer more severe infections. Again, this concept is well exemplified by measles. This disease carries a case fatality rate of $3-5 \%$ in parts of Africa, and this mortality rate is 400 times greater than in Europe. There is now good evidence that this difference is due to the poor nutrition of the African child and, similarly, the decline in severity of measles in Europe over the last 100 years mirrors the general improvement of the nutrition of children. Although a decline in the severity of the disease may be hoped for as the nutrition of the child population improves, we are unlikely to have to wait for this, as the decreasing cost of the vaccine is making effective programmes of immunization in all parts of the world a real possibility.

Measles is of course not alone in having a severe effect on the nutrition of the child. Other diseases that can be prevented by inoculation may also have a disastrous effect, such as whooping cough and tuberculosis. Whooping cough is described in the older English literature as a cause of marasmus, and this was seen in West Africa, and has also been reported from India.

This close association between malnutrition and infection suggests that adequate 
immunization of the child must have a high priority for nutrition workers. In terms of cost effectiveness, money spent on protecting the child against infection is almost certainly the most effective method of improving his nutrition.

\section{Conclusions}

The importance of nutrition education in rural communities is only slowly being appreciated. With new methods of approach to the parents, and with the weight chart of the child as a tool, those children most in need of help can be discovered, and effectiveness of the nutrition education can be evaluated through the changes in the child's weight curve. If this educational programme can be linked with an effective immunization programme against measles, whooping cough and tuberculosis, rapid improvement in child nutrition can be expected.

\section{REFERENCES}

Bengoa, J. M. (1967). F. trop. Pediat. 13, 169.

Fuglesang, A. (1969). Communicating with the Illiterate. Duplicated report of the National Food and Nutrition Commission, PO Box 2669, Lusaka, Zambia.

Holmes, A. C. (1964). Health Education in Developing Contries. London: Nelson.

King, K. W., Beghin, I. D., Fougere, W., Dominique, G., Grinker, R. \& Foucauld, J. (ro68). Archos lat.-am. Nutr. I8, 245 .

Morley, D., Woodland, M. \& Martin, W. J. (1963). F. Hyg., Camb. 6r, i 5.

Morley, D. (1968a). Trop. geogr. Med. 20, гог.

Morley, D. (г $968 b$ ). Trans. R. Soc. trop. Med. Hyg. 62, 200.

Scrimshaw, N. S., Taylor, C. E. W. \& Gordon, J. E. (1968). Monograph Ser. W.H.O. no. 57. 